\author{
Kinetics of Elementary Processes Relevant to Incipient Soot Formation \\ PI : M. C. Lin \\ Co-PI : M. C. Heaven \\ Department of Chemistry \\ Emory University,Atlanta, GA 30322 \\ chemmcl@emory.edu, heaven@euch4e.chem.emory.edu
}

\title{
I. Program Scope
}

Soot formation and abatement processes are some of the most important and challenging problems in hydrocarbon combustion. The key reactions involved in the formation of polycyclic aromatic hydrocarbons (PAH's), the precursors to soot, remain elusive. Small aromatic species such as $\mathrm{C}_{5} \mathrm{H}_{5}, \mathrm{C}_{6} \mathrm{H}_{6}$ and their derivatives are believed to play a pivotal role in incipient soot formation.

The goal of this project is to establish a kinetic database for elementary reactions relevant to soot formation in its incipient stages. In the past year, we have completed by CRDS the kinetics for the formation and decomposition of $\mathrm{C}_{6} \mathrm{H}_{5} \mathrm{C}_{2} \mathrm{H}_{2} \mathrm{O}_{2}$ in the $\mathrm{C}_{6} \mathrm{H}_{5} \mathrm{C}_{2} \mathrm{H}_{2}+\mathrm{O}_{2}$ reaction and the formation of $\mathrm{C}_{10} \mathrm{H}_{7} \mathrm{O}_{2}$ in the $\mathrm{C}_{10} \mathrm{H}_{7}$ $+\mathrm{O}_{2}$ reaction by directly monitoring $\mathrm{C}_{6} \mathrm{H}_{5} \mathrm{C}_{2} \mathrm{H}_{2} \mathrm{O}_{2}$ and $\mathrm{C}_{10} \mathrm{H}_{7} \mathrm{O}_{2}$ radicals in the visible region; their mechanisms have been elucidated computationally by quantum-chemical calculations. The $\mathrm{O}+\mathrm{C}_{2} \mathrm{H}_{5} \mathrm{OH}$ reaction has been studied experimentally and computationally and the $\mathrm{OH}+\mathrm{HNCN}$ reaction has been investigated by $a b$ initio molecular orbital calculation. In addition, a new pulsed slit molecular beam system has been constructed and tested for spectroscopic studies of aromatic radicals and their derivatives by the cavity ringdown technique (CRDS).

\section{Recent Progress}

\section{1. $\mathrm{C}_{6} \mathrm{H}_{5} \mathrm{C}_{2} \mathrm{H}_{2}+\mathrm{O}_{2} \rightarrow \mathrm{C}_{6} \mathrm{H}_{5} \mathrm{C}_{2} \mathrm{H}_{2} \mathrm{O}_{2} \rightarrow \mathrm{C}_{6} \mathrm{H}_{5} \mathrm{CHO}+\mathrm{CHO}$ (ref. \# 1)}

The $\mathrm{C}_{6} \mathrm{H}_{5} \mathrm{C}_{2} \mathrm{H}_{2}$ radical is the key intermediate of the $\mathrm{C}_{6} \mathrm{H}_{5}+\mathrm{C}_{2} \mathrm{H}_{2}$ reaction which plays a pivotal role in the formation of the second aromatic ring., ${ }^{2,3}$ The effects of temperature and pressure on the formation and decomposition of $\mathrm{C}_{6} \mathrm{H}_{5} \mathrm{C}_{2} \mathrm{H}_{2} \mathrm{O}_{2}$ in the $\mathrm{C}_{6} \mathrm{H}_{5} \mathrm{C}_{2} \mathrm{H}_{2}+\mathrm{O}_{2}$ reaction (which competes with the formation of PAHs) have been investigated at temperatures from 298 - $378 \mathrm{~K}$ by directly monitoring the $\mathrm{C}_{6} \mathrm{H}_{5} \mathrm{C}_{2} \mathrm{H}_{2} \mathrm{O}_{2}$ radical in the visible region with CRDS. The rate constant for the $\mathrm{C}_{6} \mathrm{H}_{5} \mathrm{C}_{2} \mathrm{H}_{2}+\mathrm{O}_{2}$ association and that for fragmentation of $\mathrm{C}_{6} \mathrm{H}_{5} \mathrm{C}_{2} \mathrm{H}_{2} \mathrm{O}_{2}$ were found to be respectively

$$
\begin{aligned}
& k_{1}\left(\mathrm{C}_{6} \mathrm{H}_{5} \mathrm{C}_{2} \mathrm{H}_{2}+\mathrm{O}_{2} \rightarrow \mathrm{C}_{6} \mathrm{H}_{5} \mathrm{C}_{2} \mathrm{H}_{2} \mathrm{O}_{2}\right)=(3.20 \pm 1.19) \times 10^{11} \exp (+760 / \mathrm{T}) \mathrm{cm}^{3} \mathrm{~mol}^{-1} \mathrm{~s}^{-1} \\
& k_{2}\left(\mathrm{C}_{6} \mathrm{H}_{5} \mathrm{C}_{2} \mathrm{H}_{2} \mathrm{O}_{2} \rightarrow \mathrm{C}_{6} \mathrm{H}_{5} \mathrm{CHO}+\mathrm{HCO}\right)=(1.68 \pm 0.13) \times 10^{4} \mathrm{~s}^{-1}
\end{aligned}
$$

Both reactions rates, $k_{1}$ and $k_{2}$, were found to be independent of pressure in the range of $40-80$ Torr Ar. The mechanism for this very fast reaction has been elucidated quantum-chemically by B3LYP/6-31G(d,p) calculations. The result of the calculations indicate that the reaction effectively occur by two competitive association paths giving 3- and 4-member-ring peroxide intermediates which fragment rapidly to $\mathrm{C}_{6} \mathrm{H}_{5} \mathrm{CHO}$ $+\mathrm{CHO}$ with a predicted $382 \mathrm{~kJ} / \mathrm{mol}$ exothermicity.

Additional kinetic measurements by PLP/MS and a more detailed computational study of the mechanism and associated kinetics have been done for interpretation of measured temperature dependent data. The result of our preliminary calculation for its removal by $\mathrm{O}_{2}$ measured by the CRDS and PLP/MS techniques suggests that $\mathrm{C}_{6} \mathrm{H}_{5} \mathrm{CHO}$ could be formed exothermically. Our mass-spectrometric measurements indeed show that $\mathrm{C}_{6} \mathrm{H}_{5} \mathrm{CHO}$ was produced in the $\mathrm{C}_{6} \mathrm{H}_{5} \mathrm{C}_{2} \mathrm{H}_{2}+\mathrm{O}_{2}$ reaction as predicted by the mechanism as mentioned above. The mass-spectrometric result also indicates that the formation of $\mathrm{C}_{6} \mathrm{H}_{5} \mathrm{CHO}$ from the decomposition of $\mathrm{C}_{6} \mathrm{H}_{5} \mathrm{C}_{2} \mathrm{H}_{2} \mathrm{O}_{2}$ is temperature-independent, consistent with the CRDS experimental data.

\section{Kinetics of 1- and 2- naphthyl $\left(\mathrm{C}_{10} \mathrm{H}_{7}\right)$ radical reactions (pub. $\left.\# 6^{4}\right)$}

Naphthyl radicals play a very significant role in the formation of larger PAHs during incipient soot formation stages. ${ }^{2,5}$ In a kinetic modeling of soot-formation, computed the rate constant for 1-naphthyl reaction with $\mathrm{C}_{2} \mathrm{H}_{2}$ with TST and QRRK based on the transition-state parameters obtained by B3L YP/cc- 
pVDZ calculations. Marinov et al. ${ }^{6}$ proposed the reaction rate of $1-\mathrm{C}_{10} \mathrm{H}_{7}+\mathrm{O}_{2}$ producing $\mathrm{C}_{10} \mathrm{H}_{7} \mathrm{O}+\mathrm{O}$ in the kinetic modeling of a laminar premixed $\mathrm{n}$-butane flame as $1 \times 10^{13} \mathrm{~cm}^{3} / \mathrm{mol}-\mathrm{s}$. In 2002, and his coworkers calculated the reaction rate of $1-\mathrm{C}_{10} \mathrm{H}_{7}+\mathrm{O}_{2} \rightarrow \mathrm{C}_{10} \mathrm{H}_{7} \mathrm{O}+\mathrm{O}$ with hybrid DFT molecular orbital method at the B3LYP/6-31G(d) level. The $\mathrm{C}_{10} \mathrm{H}_{7}+\mathrm{O}_{2}$ reaction at $\mathrm{T} \geq 1000 \mathrm{~K}$ is believed to occur primarily via the metathetical process, $\mathrm{C}_{10} \mathrm{H}_{7}+\mathrm{O}_{2} \rightarrow \mathrm{C}_{10} \mathrm{H}_{7} \mathrm{O}+\mathrm{O}$ leading to the formation of a naphthyloxy radical which then can fragment yielding the $\mathrm{C}_{9} \mathrm{H}_{7}+\mathrm{CO}$ products. Similarly to the reactions of $\mathrm{C}_{6} \mathrm{H}_{5}+\mathrm{O}_{2}$ and $\mathrm{C}_{6} \mathrm{H}_{5} \mathrm{C}_{2} \mathrm{H}_{2}+$ $\mathrm{O}_{2}$, the $\mathrm{C}_{10} \mathrm{H}_{7}+\mathrm{O}_{2}$ reaction at low temperature has been shown to proceed by the addition-stabilization process giving rise to the naphthylperoxy radical, $\mathrm{C}_{10} \mathrm{H}_{7}+\mathrm{O}_{2} \rightarrow \mathrm{C}_{10} \mathrm{H}_{7} \mathrm{OO}$. To our knowledge, however, there are no experimental kinetic data on the reactions despite of several theoretical studies by Green, Howard and coworkers ${ }^{2}$ and Kunioshi ${ }^{7}$. In this study we investigated the effects of temperature on the formation of $\mathrm{C}_{10} \mathrm{H}_{7} \mathrm{O}_{2}$ in the $2-\mathrm{C}_{10} \mathrm{H}_{7}+\mathrm{O}_{2}$ reaction at temperatures from $299-444 \mathrm{~K}$ by directly monitoring the $\mathrm{C}_{10} \mathrm{H}_{7} \mathrm{O}_{2}$ radical in the visible region with CRDS, as have been demonstrated successfully in the kinetic measurements of the $\mathrm{C}_{6} \mathrm{H}_{5}+\mathrm{O}_{2}$ and $\mathrm{C}_{6} \mathrm{H}_{5} \mathrm{C}_{2} \mathrm{H}_{2}+\mathrm{O}_{2}$ reactions, using the 2- $\mathrm{C}_{10} \mathrm{H}_{7} \mathrm{Br}$ as a radical source by photolysis at $193 \mathrm{~nm}$.

A least-squares analysis of the measured data gives the first experimentally measured rate constant for $2-\mathrm{C}_{10} \mathrm{H}_{7}+\mathrm{O}_{2}, k_{1}=(1.53 \pm 0.10) \times 10^{12} \exp [(900 \pm 45) / \mathrm{RT}] \mathrm{cm}^{3} \mathrm{~mol}^{-1} \mathrm{~s}^{-1}$, in the temperature range of $299-$ $444 \mathrm{~K}$ at a total pressure of 40 Torr.

\section{3. $\mathrm{O}+\mathrm{C}_{2} \mathrm{H}_{5} \mathrm{OH}$ (pub. \#8)}

In collaboration with Y-P Lee's group at National Chiao Tung University in Taiwan, we have investigated the kinetics of the $\mathrm{O}+\mathrm{C}_{2} \mathrm{H}_{5} \mathrm{OH}$ reaction in a diaphragmless shock tube; this is a continuing study following the $\mathrm{O}+\mathrm{CH}_{3} \mathrm{OH}$ reaction. ${ }^{9}$ Ethanol $\left(\mathrm{C}_{2} \mathrm{H}_{5} \mathrm{OH}\right)$ is an important and versatile renewable energy source; it may be used as a neat fuel, as an oxygenate additive, or a fuel extender in an internal engine via combustion. ${ }^{10}$ Experimentally $\mathrm{O}$ atoms were generated by photolysis of $\mathrm{SO}_{2}$ at $193 \mathrm{~nm}$ with an ArF excimer laser; their concentrations were monitored via atomic resonance absorption. Combination of our new data in the range 886 - $1410 \mathrm{~K}$ with previous measurements at low temperature represents the rate coefficients determined for the temperature range $298-1410 \mathrm{~K}$ by the equation: $k(\mathrm{~T})=(2.89 \pm 0.09) \times 10^{-16} \mathrm{~T}^{1.62} \exp [-$ $(1210 \pm 90) / T] \mathrm{cm}^{3}$ molecule ${ }^{-1} \mathrm{~s}^{-1}$; listed errors represent one standard deviation in fitting. Theoretical calculations at the CCSD(T)/6-311+G(3df, 2p)//B3LYP/6-311+G(3df) level predict potential energies of various reaction paths forming $\mathrm{CH}_{3} \mathrm{CHOH}+\mathrm{OH}(1 \mathrm{a}), \mathrm{CH}_{2} \mathrm{CH}_{2} \mathrm{OH}+\mathrm{OH}(1 \mathrm{~b})$ and $\mathrm{CH}_{3} \mathrm{CH}_{2} \mathrm{O}+\mathrm{OH}$ (1c). Rate coefficients are predicted with the canonical variational transition state (CVT) theory with the small curvature tunneling correction (SCT) method. Reaction paths associated with trans and gauche conformations are both identified; the latter accounts for $59 \pm 17 \%$ of the total product yield in the temperature range 300$3000 \mathrm{~K}$. Predicted total rate coefficients, $1.60 \times 10^{-22} \mathrm{~T}^{3.50} \exp (16 / \mathrm{T}) \mathrm{cm}^{3}$ molecule $^{-1} \mathrm{~s}^{-1}$ for the range 300$3000 \mathrm{~K}$, agree satisfactorily with experimental observations. The branching ratios of three accessible reaction channels forming $\mathrm{CH}_{3} \mathrm{CHOH}+\mathrm{OH}(1 \mathrm{a}), \mathrm{CH}_{2} \mathrm{CH}_{2} \mathrm{OH}+\mathrm{OH}(1 \mathrm{~b})$ and $\mathrm{CH}_{3} \mathrm{CH}_{2} \mathrm{O}+\mathrm{OH}$ (1c) are predicted to vary distinctively with temperature. Below $500 \mathrm{~K}$, reaction (1a) is the predominant path; the branching ratios of reactions (1b) and (1c) become $\sim 40 \%$ and $\sim 12 \%$, respectively, at $2000 \mathrm{~K}$.

\section{OH + HNCN (ref. \# 11)}

The cyanomidyl radical (HNCN) is a reactive transient species which plays an important role in a variety of chemical environments including prompt NO formation in hydrocarbon combustion, interstellar chemistry, and premordial reactions leading to the synthesis of amino acids from simple inorganic compounds. In this study the kinetics and mechanism of the reaction of cyanomidyl radical (HNCN) with hydroxyl radical $(\mathrm{OH})$ have been investigated by ab initio calculations with rate constants prediction. The single and triplet potential energy surfaces of this reaction have been calculated by single-point calculations at the CCSD(T)/6-311+G(3df,2p) level based on geometries optimized at the B3LYP/6-311+G(3df,2p) and CCSD/6-311++G(d,p) levels. The rate constants for various product channels in the temperature range of 300 - $3000 \mathrm{~K}$ are predicted by variational transition state and RRKM theories. The predicted total rate constants can be represented by the expressions $k$ (total $)=2.66 \times 10^{2} \mathrm{~T}^{4.50} \exp (239 / \mathrm{T})$ in $\mathrm{T}=300-1000 \mathrm{~K} ; 1.38 \times 10^{20}$ $\mathrm{T}^{2.78} \exp (1578 / \mathrm{T}) \mathrm{cm}^{3}$ molecule $\mathrm{s}^{-1} \mathrm{~s}^{-1}$ at $\mathrm{T}=1000-3000 \mathrm{~K}$. The branching ratios of primary channels are 
predicted: $k_{1}$ for forming singlet $\mathrm{HON}(\mathrm{H}) \mathrm{CN}$ accounts for $0.32-0.28$ and $k_{4}$ for forming singlet HONCNH accounts for $0.68-0.17$ in the temperature range of $300-800 \mathrm{~K} . k_{2}+k_{7}$ for producing $\mathrm{H}_{2} \mathrm{O}+\mathrm{NCN}$ accounts for $0.55-0.99$ in the high temperature range of $800-3000 \mathrm{~K}$. The branching ratios of $k_{3}$ for producing HCN $+\mathrm{HNO}, k_{6}$ for producing $\mathrm{H}_{2} \mathrm{~N}+\mathrm{NCO}, k_{8}$ for forming $3 \mathrm{HN}(\mathrm{OH}) \mathrm{CN}, k_{9}$ for producing $\mathrm{CNOH}+3 \mathrm{NH}$, and $k_{5}+$ $k_{10}$ for producing $\mathrm{NH}_{2}+\mathrm{NCO}$ are negligible. The rate constants for key individual product channels are provided in a table for different $\mathrm{T}, \mathrm{P}$-conditions.

\section{Development of the cavity ring-down spectrometer}

A cavity ring-down spectrometer (CRDS) for studies of aromatic radicals has been constructed. A slit-jet supersonic expansion is used to cool the radicals, and thereby simplify their electronic spectra. The radicals are generated from stable precursor molecules using a pulsed discharge.

The first attempts to record the ${ }^{2} \mathrm{~B}_{1}-\chi^{2} \mathrm{~A}_{1}$ band system (near $505 \mathrm{~nm}$ ) for jet-cooled phenyl radicals were carried out using a pulsed discharge in $\mathrm{C}_{6} \mathrm{H}_{6} / \mathrm{He}$ mixtures to generate radical species. At low discharge power, intense lines of metastable He were observed. The Swann bands of $\mathrm{C}_{2}$ appeared when the discharge voltage was increased, but the phenyl bands were not detected. Fitting to the rotational line intensity distribution of the $C_{2}$ spectrum yielded a temperature of about $100 \mathrm{~K}$, indicating that cold radical species could be generated using our discharge slit nozzle assembly. In the attempts to observe the spectrum of phenyl we carried out systematic variations of the nozzle source pressure, mole fraction of benzene, and discharge voltage. In a few experiments the He carrier gas was replaced by $\mathrm{Ar}$ or $\mathrm{N}_{2}$. We also explored alternative precursor molecules including bromobenzene and nitrosobenzene. In all instances the only molecular species observed was $\mathrm{C}_{2}$. Low energy discharges produced $\mathrm{C}_{2}$ with rotational temperatures as low as $40 \mathrm{~K}$.

As a further test of the capabilities of the new apparatus, we repeated the measurements of Motylewski and Linnartz ${ }^{12}$ on the ${ }^{2} \Pi-X^{2} \Pi$ bands of linear $\mathrm{C}_{6} \mathrm{H}$. This radical was generated using a pulsed discharge in $\mathrm{C}_{2} \mathrm{H}_{2}$. These experiments were successful, and the rotational contours of the absorption bands were consistent with a rotational temperature of $30 \mathrm{~K}$.

Attempts were also made to observe the $2^{2} \mathrm{~B}_{1}-\chi^{2} \mathrm{~B}_{1}$ transition of the phenoxyl radical near $390 \mathrm{~nm}$. Compared to the phenyl ${ }^{2} \mathrm{~B}_{1}-Z^{2} \mathrm{~A}_{1}$ transition, phenoxyl has a much larger absorption cross-section $\left(7.7 \times 10^{-18}\right.$ $\mathrm{cm}^{2}$ vs. $<5 \times 10^{-19} \mathrm{~cm}^{2}$ ). Again it was found that the discharge source was overly destructive. The $\mathrm{N}_{2}^{+} \mathrm{B}-\mathrm{X}$ bands were observed in absorption when $\mathrm{N}_{2}$ was used as the carrier gas.

Work is currently in progress to develop a less destructive radical source for work with aromatic radicals. Pulsed photolysis is know to be an effective way of generating these species, but the short duration radical pulses generated by excimer laser photolysis are not compatible with $>10$ ms ring-down times. Pulsed light sources with ms duration and flash pyrolysis nozzles are being evaluated.

\section{Future work}

We shall devote our effort to kinetic studies of phenylvinyl and naphthyl radical reactions with combustion species by CRDS and PLP/MS techniques. Spectroscopic studies of these and other small aromatic radicals by CRDS in a molecular beam will be initiated. Construction of the apparatus for these experiments has been completed, and evaluation experiments are in progress. The results of the spectroscopic studies are expected to improve the diagnostics of the radicals such as the naphthyls. Once the instrument testing and development work has been completed, the first objective will be studies of the phenyl radical. All experimental studies will be complemented by quantum chemical calculations to help elucidate the reaction mechanisms and spectroscopic data obtained.

\section{References (DOE publications denoted by *)}

1. "Temperature and Pressure Effect on Formation and Decomposition of Phenylvinylperoxy Radicals in the $\mathrm{C}_{6} \mathrm{H}_{5} \mathrm{C}_{2} \mathrm{H}_{2}+\mathrm{O}_{2}$ Reaction," J. Park and M. C. Lin, Proceedings of the Combustion Institute 32 (2008) accepted.* 
2. H. Richter, T. G. Benish, O. A. Mazyar, W. H. Green, and J. B. Howard, Proceedings of the Combustion Institute, 28:2609 (2002).

3. H. Richter, O. A. Mazyar, R. Sumathi, W. H. Green, J. B. Howard and J. W. Bozzelli, J. Phys. Chem. A. 105:1561 (2001).

4. "Kinetics and Mechanism of the $\mathrm{C}_{10} \mathrm{H}_{7}+\mathrm{O}_{2}$ Reaction", J. Park and M. C. Lin, in preparation.*

5. H. Richter, O. A. Mazyar, R. Sumathi, W. H. Green, J. B. Howard and J. W. Bozzelli, J. Phys. Chem. A. 105:1561 (2001).

6. N. M. Marinov, W. J. Pitz, C. K. Westbrook, A. M. Vincitore, M. J. Castaldi, S. M. Senkan, Combustion and Flame 114 192-213 (1998).

7. N. Kunioshi. M. Touda, S. Fukutani, Combustion and Flame 128:292-3000 (2002)

8. "Experimental and theoretical studies of rate coefficients for the reaction $\mathrm{O}\left({ }^{3} \mathrm{P}\right)+\mathrm{C}_{2} \mathrm{H}_{5} \mathrm{OH}$ at high temperatures", Chih-Wei Wu, Yuan-Pern Lee, Shucheng Xu and M. C. Lin, J. Phys. Chem. A, 111, 6693-6703 (2007).*

9. C.-W. Lu, S.-L. Chou, Y.-P. Lee, S.C. Xu, Z.F. Xu, M.C. Lin, J. Chem. Phys. 122:244314 (2005).*

10. A. C. Hansen, Q. Zhang, and P. W. L. Lyne, Bioresource Tech. 96, 277 (2005)

11. "Ab initio chemical kinetics for the $\mathrm{OH}+\mathrm{HNCN}$ reaction", S.C. Xu and M. C. Lin, J. Phys. Chem. A, $111,6730-40$ (2007).*

12. T. Motylewski and H. Linnartz, Review of Scientific Instruments 70, 1305, (1999). 